\title{
THE
}

\section{Constitutive immune function in European starlings, Sturnus vulgaris, is decreased immediately after an endurance flight in a wind tunnel}

Silke Nebel

Ulf Bauchinger

University of Rhode Island

Deborah M. Buehler

Lillie A. Langlois

University of Rhode Island

Michelle Boyles

University of Rhode Island

See next page for additional authors

Follow this and additional works at: https://digitalcommons.uri.edu/nrs_facpubs

Terms of Use

All rights reserved under copyright.

\section{Citation/Publisher Attribution}

Nebel, S., Bauchinger, U., Buehler, D. M., Langlois, L. A., Boyles, M., Gerson, A. R.,...Guglielmo, C. G. (2011). Constitutive immune function in European starlings, Sturnus vulgaris, is decreased immediately after an endurance flight in a wind tunnel. Journal of Experimental Biology, 215, 272-278. doi: 10.1242/jeb.057885 Available at: http://dx.doi.org/10.1242/jeb.057885

This Article is brought to you for free and open access by the Natural Resources Science at DigitalCommons@URI. It has been accepted for inclusion in Natural Resources Science Faculty Publications by an authorized administrator of DigitalCommons@URI. For more information, please contact digitalcommons-group@uri.edu. 


\section{Authors}

Silke Nebel, Ulf Bauchinger, Deborah M. Buehler, Lillie A. Langlois, Michelle Boyles, Alexander R. Gerson, Edwin R. Price, Scott R. McWilliams, and Christopher Guglielmo 


\title{
Constitutive immune function in European starlings, Sturnus vulgaris, is decreased immediately after an endurance flight in a wind tunnel
}

\author{
Silke Nebel ${ }^{1, \star}$, Ulf Bauchinger ${ }^{2}$, Deborah M. Buehler ${ }^{3,4}$, Lillie A. Langlois ${ }^{2}$, Michelle Boyles ${ }^{2}$, \\ Alexander R. Gerson ${ }^{1}$, Edwin R. Price ${ }^{1}$, Scott R. McWilliams ${ }^{2}$ and Christopher G. Guglielmo ${ }^{1}$ \\ ${ }^{1}$ Department of Biology, Advanced Facility for Avian Research, University of Western Ontario, London, Ontario, Canada N6A 5B7, \\ ${ }^{2}$ Department of Natural Resources Science, University of Rhode Island, Kingston, RI 02881, USA, ${ }^{3}$ Department of Natural History,

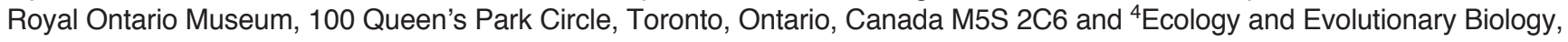 \\ University of Toronto, 25 Willcocks Street, Toronto, Ontario, Canada M5S 3B2 \\ *Author for correspondence (snebel2@uwo.ca)
}

Accepted 19 October 2011

\begin{abstract}
SUMMARY
Life-history theory predicts that animals face a trade-off in energy allocation between performing strenuous exercise, such as migratory flight, and mounting an immune response. We experimentally tested this prediction by studying immune function in European starlings, Sturnus vulgaris, flown in a wind tunnel. Specifically, we predicted that constitutive immune function decreases in response to training and, additionally, in response to immediate exercise. We compared constitutive immune function among three groups: (1) 'untrained' birds that were kept in cages and were not flown; (2) 'trained' birds that received flight training over a 15 day period and performed a $1-4 \mathrm{~h}$ continuous flight, after which they rested for $48 \mathrm{~h}$ before being sampled; and (3) 'post-flight' birds that differed from the 'trained' group only in being sampled immediately after the final flight. A bird in our trained group represents an individual during migration that has been resting between migratory flights for at least 2 days. A bird in our post-flight group represents an individual that has just completed a migratory flight and has not yet had time to recover. Three of our four indicators (haptoglobin, agglutination and lysis) showed the predicted decrease in immune function in the post-flight group, and two indicators (haptoglobin, agglutination) showed the predicted decreasing trend from the untrained to trained to post-flight group. Haptoglobin levels were negatively correlated with flight duration. No effect of training or flight was detected on leukocyte profiles. Our results suggest that in European starlings, constitutive immune function is decreased more as a result of immediate exercise than of exercise training. Because of the recent emergence of avian-borne diseases, understanding the trade-offs and challenges faced by long-distance migrants has gained a new level of relevance and urgency.
\end{abstract}

Key words: constitutive immune function, European starlings, Sturnus vulgaris, life-history trade-off, migratory flight, wind tunnel.

\section{INTRODUCTION}

The immune system is crucial for an animal's survival, but it is costly to maintain and use (Klasing, 2004; Lochmiller and Deerenberg, 2000). Immune function is increasingly understood as a life-history parameter, and as such it is subject to energy and nutrient trade-offs (Ardia and Schat, 2008; Buehler et al., 2008b; Lee, 2006; Norris and Evans, 2000; Sheldon and Verhulst, 1996; Tella et al., 2002). In situations of limited energy availability, animals must maximise fitness by differential allocation of resources to satisfy competing energetic demands (King, 1974; Willmer et al., 2000). Trade-offs between immune function and other lifehistory parameters have been documented across taxa, including insects (Kraaijeveld et al., 2001; Rolff and Siva-Jothy, 2003), reptiles (López and Martín, 2005), birds (Norris and Evans, 2000) and mammals (Graham et al., 2010).

The trade-off between the immune response and strenuous exercise is particularly well documented in human athletes. Intensive training suppresses the immune system (Gleeson, 2007; Gleeson et al., 1995; Hoffmann et al., 2010; Pedersen and Hoffmann-Goetz, 2000; Wolach et al., 1998), while strenuous exercise, or in fact any physical activity, is harder to perform when the immune system is being challenged (Apanius, 1998; Nieman, 1997). Flight is energetically much more demanding than running, as the minimum energy cost of flying is thought to be about twice the maximal oxygen consumption $\left(\dot{V}_{\mathrm{O}_{2} \text {,max }}\right)$ compared with a running mammal of similar body size (Butler and Woakes, 1990). It remains comparatively little understood, however, whether migratory flight suppresses immune function or whether immune-challenged birds have a lowered flight performance (Ardia and Schat, 2008; Buehler and Piersma, 2008; Buehler et al., 2010a). It is, however, particularly relevant in the context of the transmission of avian-borne diseases. Migratory birds are often blamed for the spread of avian influenza, but little is known about whether birds infected with highly pathogenic avian influenza can actually perform a long-distance migration (Altizer et al., 2011). Natural infection with lowpathogenic avian influenza hampered flight performance in migratory Bewick's swans, Cygnus columbianus (Van Gils et al., 2007), but an experimental study failed to find an effect of the equivalent of a $1500 \mathrm{~km}$ flight in a wind tunnel on immune function in red knots, Calidris canutus (Hasselquist et al., 2007).

Here, we studied this trade-off by conducting a wind tunnel experiment with three groups of European starlings, Sturnus vulgaris L.: 'trained', 'untrained' and 'post-flight'. The acquired arm of the immune system seems generally less affected by training and intensive 
exercise than the innate arm (Baj et al., 1994; Nieman et al., 1995; Tvede et al., 1991). We therefore focused on the constitutive aspects of the innate arm of the immune system and predicted that constitutive immune function decreases in response to training and, additionally, in response to immediate exercise. Birds in our trained group mimic individuals during migration that have been resting between migratory flights for at least 2 days. Birds in our post-flight group represent individuals that have just completed a migratory flight and have not yet had time to recover. Birds in the untrained group represent birds that did not perform a migratory flight and serve as a control. We hoped to thereby elucidate whether reduced immune measurements at a stopover site are a short-term response to flight rather than a reduced immunity associated with the whole migratory period.

We measured four components of the constitutive (non-inducible) branch of the immune system, which represents the birds' first line of defence. It may thus be important during short stopovers between migratory flights when there is not enough time to mount an acquired response (Schmid-Hempel and Ebert, 2003). Constitutive immune function must be maintained even when not in use, generating costs that may be important in the physiological trade-off with migratory flight (Buehler et al., 2008b; Martin et al., 2008). Specifically, we measured the activity of haptoglobin (Matson, 2006), an acute phase protein that offers protection against harmful end products of the immune response (Delers et al., 1988). We employed the haemolysis-haemagglutination assay (Matson et al., 2005) to quantify complement-like and natural antibody activity, respectively, which provide the first defence against spreading infections via cell lysis (Ochsenbein and Zinkernagel, 2000). And we examined leukocyte concentrations, which are indicative of circulating cellular immunity (Campbell, 1995).

We tested three predictions generated by the hypothesised lifehistory trade-off between mounting an immune response and satisfying the costs of exercise: constitutive immunity is lower (1) in post-flight birds compared with untrained birds, (2) in post-flight birds compared with trained birds that have had 2 days to recover from flight, and (3) in trained birds that had not flown for 2 days compared with untrained birds.

\section{MATERIALS AND METHODS}

\section{Bird capture and husbandry}

All European starlings used in this study were captured during July 2009 in the vicinity of London, Ontario, Canada $\left(43.17^{\circ} \mathrm{N}, 81.32^{\circ} \mathrm{E}\right)$. Starlings in the Great Lakes region only migrate short distances (Dolbeer, 1982); it may therefore be possible that flights of a few hours duration constitute intense exercise for these individuals. Birds were maintained in large aviaries (two sizes: $3.7 \times 2.4 \times 3.1 \mathrm{~m}$ or $2.3 \times 2.4 \times 3.5 \mathrm{~m}$ ) until the beginning of the experiment in September 2009 when they were held in individual cages in a single room. The birds used in this study were part of a larger project that involved studying the effects of different diets on energetics during flight. All diets were isocaloric, had the same macronutrient composition ( $41 \%$ carbohydrate: $13 \%$ protein: $30 \%$ fat), and differed only in the relative amounts of plant oils that comprised the dietary fat (olive oil, sunflower oil) and the amount of supplementary vitamin E (5 or $30 \mathrm{IU} \mathrm{kg}^{-1}$ diet). We found no differences in any of the constitutive immunity measures between diets (general linear model; $P>0.2$ ), so we pooled these data for the remainder of the analyses reported here.

\section{Experimental groups and flights}

Birds were randomly assigned to one of the three treatment groups. Untrained birds $(N=55)$ were housed in the large aviaries and never flew in the wind tunnel; all other birds were flown together in randomly assigned groups of three in the wind tunnel at $12 \mathrm{~m} \mathrm{~s}^{-1}$ and $15^{\circ} \mathrm{C}$ for 15 consecutive days according to the following schedule: days 1 and 2, $10 \mathrm{~min}$; day $3=20 \mathrm{~min}$; days 4 and 5, $30 \mathrm{~min}$; day 6, $45 \mathrm{~min}$; day 7, 60 min; day 8, $90 \mathrm{~min}$; day 9, $30 \mathrm{~min}$; day 10, $120 \mathrm{~min}$; day 11, $180 \mathrm{~min}$; day 12, no flight training; day 13, $60 \mathrm{~min}$; day 14, $30 \mathrm{~min}$; day 15, $240 \mathrm{~min}$. On day 16, birds were flown together in randomly assigned groups of three for as long as they voluntarily flew (up to $4 \mathrm{~h}$ ). We either sampled blood immediately after this final flight (post-flight, $N=16$ ) or $48 \mathrm{~h}$ afterwards (trained, $N=29$ ). In this way, trained and post-flight birds had very similar total flight times over the 16 days of exercise training with the primary difference between these two groups being whether we sampled the bird's blood immediately after flight (post-flight) or 2 days after their final flight (trained). All animal care protocols followed the Canadian Council on Animal Care guidelines and were approved by the University of Western Ontario Council on Animal Care and the Animal Use Subcommittee (protocol no. 2006-01104) and by the Institutional Animal Care and Use Committee at the University of Rhode Island (AN08-02-014).

\section{Wind tunnel set-up}

Birds were flown in a recirculating wind tunnel at the Advanced Facility for Avian Research at the University of Western Ontario. The test section is enclosed in a plenum (approximately $4 \times 5 \times 2.5 \mathrm{~m}$ high), which allows for precise control of temperature between -15 and $30^{\circ} \mathrm{C}$ and humidity between $10 \%$ and $90 \%$ RH. The closed portion of the test section is a $2 \mathrm{~m}$ long octagon with $1 \mathrm{~m}$ vertical and $1.5 \mathrm{~m}$ horizontal dimensions. A $0.5 \mathrm{~m}$ long open section at the rear of the test section allows birds to enter and exit the air stream with minimal disturbance to the flow. True air speed can be controlled between approximately 2 and $21 \mathrm{~m} \mathrm{~s}^{-1}$. Without an upstream net and outside of the wall boundary layer velocity uniformity (standard deviation of velocity) is $0.5 \%$ and turbulence intensity ranges between $0.12 \%$ and $0.27 \%$ (Gerson and Guglielmo, 2011). In this study, birds were flown with a net $(0.15 \mathrm{~mm}$ filament thickness, $2.5 \times 2.5 \mathrm{~cm}$ mesh) at the front of the test section.

\section{Blood collection}

Blood samples were taken from untrained and trained birds usually within $10 \mathrm{~min}$ ( $25 \mathrm{~min}$ if a second bird was sampled on any given day) of capture from their cages. Blood samples were taken from post-flight birds within $5 \mathrm{~min}$ of completion of their final flight. Birds were anaesthetised by inhaling isoflurane and decapitated for the study of the effect of diet on tissue composition (see 'Bird capture and husbandry'). From each bird, we collected $c a .1 \mathrm{ml}$ arterial blood into a heparinised $1.5 \mathrm{ml}$ microcentrifuge tube. Immediately after sampling we made two blood smears on glass slides (Campbell, 1995); the remainder of the blood was processed within $1 \mathrm{~h}$ of sampling. Plasma was obtained by centrifuging blood samples for $10 \mathrm{~min}$ at $12,000 \mathrm{~g}$ and stored at $-80^{\circ} \mathrm{C}$ until processing. At time of blood sampling, we also measured body mass with an electronic balance to the nearest $0.1 \mathrm{~g}$, and tarsus length with digital calipers to the nearest $0.01 \mathrm{~mm}$.

\section{Measuring immune function}

Haptoglobin is an acute phase protein that offers protection against harmful end products of the immune response (Delers et al., 1988). To quantify plasma haptoglobin levels, we followed the 'manual method' in a commercial kit (no. TP801; Tri-Delta Diagnostics, Morris Plains, NJ, USA), which exploits the peroxidase activity of haptoglobin bound to haemoglobin. 
The haemolysis-haemagglutination assay quantifies complementlike and natural antibody activity, which provides the first line of defence against spreading infections via cell lysis (Ochsenbein and Zinkernagel, 2000). The agglutination reaction measures blood clumping caused by the interaction between natural antibodies and antigens in rabbit erythrocytes. The lytic reaction measures the amount of haemoglobin released from the lysis of rabbit erythrocytes. In both cases, quantification is achieved by serial dilution of plasma samples and assessment of the dilution step at which either the agglutination or the lysis reaction stopped (Matson et al., 2005). Specifically, we placed $25 \mu$ l of plasma in the first two rows of a 96-well round-bottomed plate. From rows 2-11, we performed ten 1:2 dilutions using Dulbecco's PBS. We then added $25 \mu \mathrm{l}$ of $1 \%$ rabbit red blood cell suspension to each well and placed the plates in a water bath at $37^{\circ} \mathrm{C}$ for $90 \mathrm{~min}$. Afterwards, we tilted the plates $45 \mathrm{deg}$ and then scanned them (HP Scanjet G3110) after $20 \mathrm{~min}$ for agglutination and after $90 \mathrm{~min}$ for lysis. The scans were scored blindly by a single observer (S.N.) using the criteria outlined elsewhere (Matson et al., 2005).

The concentrations of the different types of leukocytes are indicative of different aspects of the immune function (Campbell, 1995). Heterophils are phagocytes that respond immediately to novel pathogens during the initial immune response. They are the counterparts of the mammalian neutrophils and form the first line of cellular defence against invading microbial pathogens. Inflammation or infectious conditions cause a dramatic influx of heterophils (Juul-Madsen et al., 2008). Eosinophils are cytotoxic cells with the ability to kill other cells as well as large extracellular parasites. Lymphocytes orchestrate the antibody and cell-mediated functions of the acquired immune system. Monocytes link constitutive, non-specific (innate) immunity to induced, specific (acquired) immune functions. They are precursors of macrophages, which are involved in initiating and directing the innate and specific immune responses, the systemic acute phase response, tissue repair and tissue remodelling (Klasing, 1998). Thrombocytes play a role in blood clotting and are also phagocytic (Campbell, 1995).

Blood smears were fixed in $100 \%$ methanol prior to staining in Hemacolor stain set (Harleco, Gibbstown, NJ, USA) and examined at $\times 1000$ magnification with oil immersion. The first 100 leukocytes were counted and classified as heterophils, eosinophils, lymphocytes or monocytes. While counting the first 100 leukocytes, we also recorded the number of thrombocytes seen as an estimate of the relative number of thrombocytes per leukocyte (Buehler et al., 2008b). In combination with the blood smears, we obtained total leukocyte concentrations using the indirect eosinophil Unopette method (Campbell, 1995), following the manufacturer's instructions (No. 5877, Becton Dickinson, Franklin Lakes, NJ, USA). Note that the sample size differs among assays based on plasma availability.

\section{Statistical analyses}

To eliminate between-plate variation in haptoglobin data, we normalised the distribution of each plate by subtracting the mean from each value and dividing it by the standard deviation, yielding a $z$-score with a mean of zero (Zar, 1999). Agglutination data were squared, lysis data square-root transformed, and leukocyte data $\log _{10}$ $(x+0.001)$ transformed to meet the assumptions of normality and equal variance.

To compare immune function among treatment groups, we grouped the soluble immune components (haptoglobin, agglutination and lysis) and the cellular components (leukocyte counts) and analysed both sets of data using a multivariate analysis of variance (MANOVA). To control for body mass differences, we regressed body mass against tarsus length and included the residuals as a covariate. 'Treatment group' was the main factor and 'training group' was included as a covariate. Flights of less than 60 min duration $(N=8)$ were excluded from this analysis. To verify whether the MANOVA revealed significant differences among groups, we used the Pillai trace test statistic, as it is considered to be less sensitive to deviations from assumptions than other multivariate statistics (Johnson and Field, 1993; Olson, 1976). Among-group comparisons were evaluated using Hotelling's $T$-square statistic. When the Pillai trace test was significant, we performed one-tailed $t$-tests to describe how each individual immune indicator varied with experimental treatment. We present two- and one-tailed tests as we predict the direction of the expected effect (Sokal and Rohlf, 1995); namely, decreased immune function in the post-flight compared with the untrained as well as the trained group and in the trained compared with the untrained group.

We also tested for an effect of experimental flight duration on immune indicators while controlling for experimental group using the general linear model (GLM) package (type III sum of squares). Here, flights of all durations were included. We used visual examination of the distribution of the residuals of the GLM to evaluate normality of the data distribution (Zuur et al., 2009). The mean final flight duration (including flights of less than $60 \mathrm{~min}$ ) was $142 \mathrm{~min}(N=53$; range $7-431 \mathrm{~min}$, s.d. 79.261). The birds in the postflight group (mean $180 \mathrm{~min}$ ) flew on average longer $(t=2.492$; d.f. $=52, P=0016)$ than those in the trained group (mean $124 \mathrm{~min}$ ). All analyses were performed with the statistical software SYSTAT v.13 (SYSTAT ${ }^{\circledR} 13$ Statistics I II III IV, SYSTAT Software Inc., www.systat.com).

\section{RESULTS \\ MANOVA}

Size-corrected body mass did not affect haptoglobin, agglutination or lysis scores (Pillai trace $=0.044$, d.f. $=3,47, P=0.541$ ), nor did flight group (Pillai trace $=0.462$, d.f. $=18,147, P=0.103$ ). Experimental treatment, however, significantly affected these three measures of immune function (Pillai trace $=0.291$, d.f. $=6,96, P=0.018$ ). Pair-wise comparisons showed that the post-flight group differed significantly from the trained group (Hotelling's $T$-square $=28.554, P<0.001$ ) and from the untrained group (Hotelling's $T$-square $=16.175, P=0.003$ ) while the trained and untrained groups did not differ (Hotelling's $T$-square $=6.430, P=0.126$ ).

\section{Haptoglobin}

Plasma haptoglobin concentration decreased from the untrained group to the trained group, and was lowest in the post-flight group. The mean of the untrained group was higher than that of the postflight group (pooled variance: $t=1.976$, d.f. $=57$, one-tailed $t$-test $P=0.027)$. There was no significant difference between untrained and trained (pooled variance: $t=0.953$, d.f. $=68$, one-tailed $P=0.172$ ), or between trained and post-flight groups (pooled variance: $t=-1.088$, d.f. $=37$, one-tailed $P=0.142$; Fig. 1 A).

We then tested for an effect of group and flight time on haptoglobin concentration. There was no interaction between flight time and group $\left(F_{1,40}=0.208, P=0.651\right)$, nor was there an effect of group $\left(F_{1,40}=0.665, P=0.420\right)$. We therefore pooled birds from the two groups and showed that plasma haptoglobin concentration decreased with increasing flight duration $\left(F_{1,42}=7.241, P=0.001\right.$, $r^{2}=0.147$; Fig. 2). Removal of the longest flight ( $\left.431 \mathrm{~min}\right)$ did not alter the result $\left(F_{1,41}=4.817, P=0.034\right)$. 


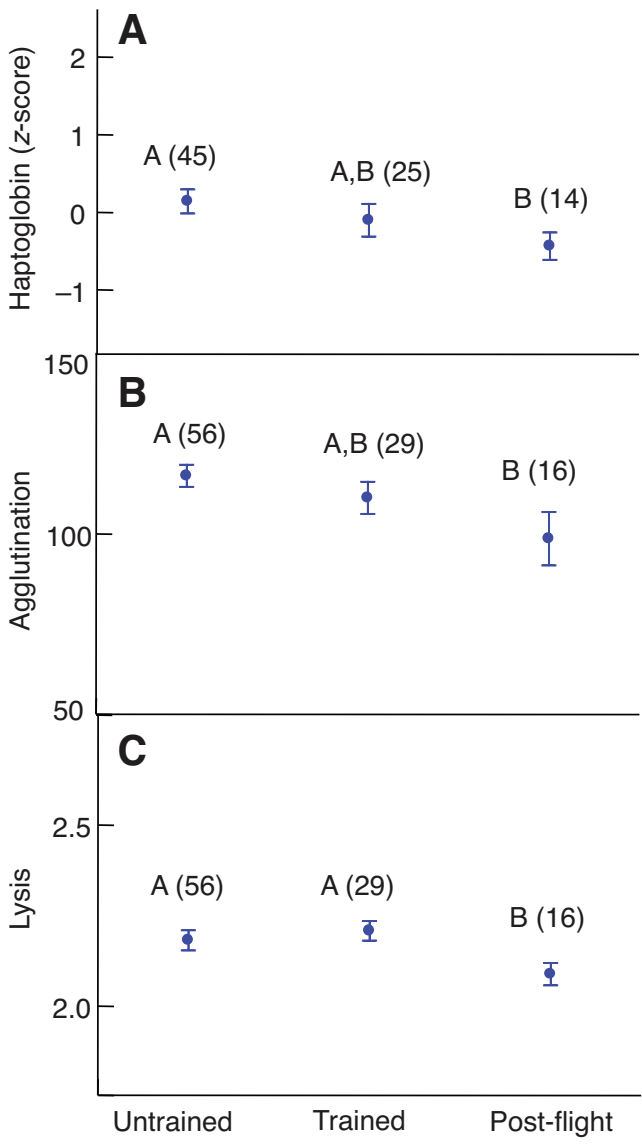

Fig. 1. Three measures of constitutive immune function in untrained, trained and post-flight European starlings. Untrained birds were kept in cages and not flown, trained birds were sampled $48 \mathrm{~h}$ after a continuous $1-4 \mathrm{~h}$ flight, and post-flight birds were sampled immediately after a continuous $1-4 \mathrm{~h}$ flight. Sample sizes are given in parentheses, and letters indicate amonggroup differences. (A) Plasma haptoglobin concentration ( $z$-score \pm 1 s.e.m.). (B) Agglutination scores (squared \pm 1 s.e.m.). (C) Lysis scores (square root \pm 1 s.e.m.).

\section{Agglutination}

We also saw a decrease in agglutination scores from the untrained group to the trained group to the post-flight group. The mean of the untrained group was higher than that of the post-flight group (pooled variance: $t=2.557$, d.f. $=70$, one-tailed $P=0.006$ ) and trained birds also tended to have higher agglutination than post-flight birds (pooled variance: $t=-1.430$, d.f. $=43$, one-tailed $P=0.080$; Fig. 1B). Trained and untrained birds did not differ (pooled variance: $t=1.163$, d.f. $=83$, one-tailed $P=0.124$ ). We did not find an effect of flight time on agglutination scores (group: $F_{1,48}=1.865, P=0.178$; flight time: $F_{1,48}=0.905, P=0.346$ ).

\section{Lysis}

The pattern of lysis scores differed somewhat from those shown for haptoglobin and agglutination as the trained group did not differ from the untrained group. However, as with the other immune data, the post-flight group scored lowest. Both untrained birds and trained birds had higher scores than post-flight birds (separate variance: $t=2.328$, d.f. $=43$, one-tailed $P=0.012$; pooled variance: $t=-2.817$, d.f. $=43$, one-tailed $P=0.004)$, but untrained and trained birds were not different (pooled variance: $t=-0.606$, d.f. $=83$, onetailed $P=0.727$; Fig. 1C). We did not find an effect of flight time

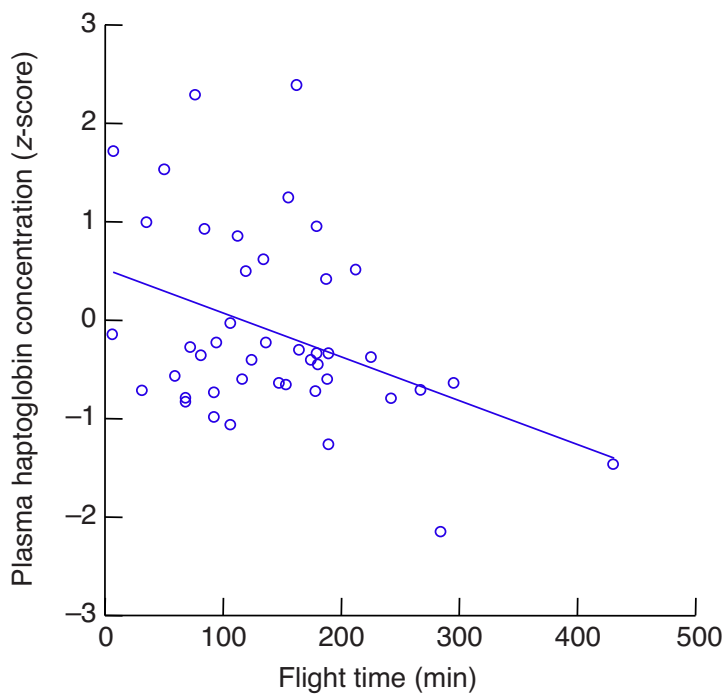

Fig. 2. Plasma haptoglobin concentration decreased with experimental flight duration, irrespective of experimental group.

on lysis scores (group: $F_{1,48}=7.638, P=0.008$; flight time: $\left.F_{1,48}=0.056, P=0.813\right)$.

\section{Leukocyte concentration}

No effect of experimental group on either total leukocyte concentration or the concentration of any type of leukocyte was detected (Pillai trace $=1.460$, d.f. $=12,8, P=0.205$; Table 1), nor was there an effect of size-corrected body mass (Pillai trace $=0.749$, d.f. $=6,3, P=0.399$ ) or flight group (Pillai trace=2.674, d.f.=36,48, $P=0.407)$. We also did not detect any significant changes in total leukocyte concentration or the concentration of any type of leukocyte with flight time ( $P>0.6$, data not shown).

\section{DISCUSSION}

In European starlings, three out of four indicators of the constitutive immune system decreased immediately after an endurance flight in a wind tunnel. These results are consistent with the predicted tradeoff between constitutive immune function and intense exercise. Constitutive immune function is maintained even when not actively fighting an infection, and the costs of maintaining it are thus considered to be important in the physiological trade-off with migratory flight (Buehler et al., 2008b; Martin et al., 2008). These results add to the growing body of evidence supporting an energetic trade-off between immune function and other life-history traits. For example, studies in birds have shown that immune function is negatively related to reproductive effort (Ardia, 2005; Deerenberg et al., 1997; Lochmiller and Deerenberg, 2000; Moreno et al., 1999; Norris and Evans, 2000), growth rate (Mauck et al., 2005) and rapid feather growth during moult (Martin, 2005). Likewise, experimentally inducing immune responses leads to a decrease in body condition (Sanz et al., 2004) and nestling growth (AlonsoAlvarez and Tella, 2001).

This is the first study to examine constitutive immune function in the context of training (trained) versus the immediate effect of exercise (post-flight). The physiological demands placed upon individuals in the two groups resemble those experienced by birds during the migratory period; namely, birds that have been resting between migratory flights for at least 2 days, and birds that have just completed a migratory flight. Lysis was lower in post-flight 
Table 1. Mean leukocyte concentrations ( \pm s.d.) in the three experimental groups

\begin{tabular}{lccc}
\hline Leukocyte type $\left(\mu l^{-1}\right)$ & Untrained $(N=18)$ & Trained $(N=8)$ & Post-flight $(N=6)$ \\
\hline Total leukocytes & $46,219 \pm 32,637$ & $55,860 \pm 44,771$ & $40,738 \pm 28,620$ \\
Heterophils & $18,535 \pm 13,828$ & $20.566 \pm 37,418$ & $14,739 \pm 12,949$ \\
Eosinophils & $1998 \pm 2228$ & $2709 \pm 2073$ & $4650 \pm 5242$ \\
Lymphocytes & $22,073 \pm 27,012$ & $28,230 \pm 17,150$ & $18,049 \pm 16,927$ \\
Monocytes & $3612 \pm 2718$ & $4453 \pm 4252$ & $3300 \pm 2390$ \\
Thrombocytes & $154,616 \pm 115,181$ & $98,377 \pm 62,865$ & $93,767 \pm 49,311$ \\
\hline
\end{tabular}

Birds that flew for less than $60 \mathrm{~min}$ in their final flight are not included. $N$, number of birds.

than in trained birds, and haptoglobin and agglutination showed the same trend. These results can be interpreted in two ways. (1) Constitutive immune function decreases in response to being in the migratory state (trained), and decreases further as an immediate effect of having performed a migratory flight (post-flight). (2) Constitutive immune function decreases in response to exercise, but recovers again within a short time period.

A recent study on red knots provides support for the second explanation. In red knots $C$. $c$. rufa caught during a migratory stopover at Delaware Bay, USA, haptoglobin and lysis scores were higher in birds storing fuel for subsequent flight (presumed equivalent to our 'trained' birds) than in those recovering immediately after a preceding flight (our post-flight group) (Buehler et al., 2010b). Assuming that the recovering birds arrived more recently than those depositing fuel stores, two possible explanations for their finding are discussed. First, fuelling birds may experience an increased rate of infection or may be bolstering their immune defence in response to high antigen exposure. Second, birds recovering from flight may be immuno-compromised because of the physical strain of migratory flight or as a result of adaptive tradeoffs between immune function and migration. Our results are consistent with their second hypothesis. Contrary to our results, Buehler and colleagues did not find an effect of migratory flight on agglutination (Buehler et al., 2010b). It is possible that the effect of flight on immune measures differs between species.

We did not find a difference among experimental groups in the concentration of any type of leukocyte. This may be for one of five reasons. (1) The leukocyte profiles in our study were highly variable (Table 1), which is consistent with other studies (Buehler et al., 2010b), and so the effect size was too small to be detected with the available sample size. (2) The flight time was not long enough to result in a difference in leukocyte profiles. The average flight duration was somewhat longer than $2 \mathrm{~h}$, but studies in other taxa have shown that the initial leukocyte response to strenuous exercise only becomes apparent after a time span of hours or even days (Cardinet et al., 1964; Davis et al., 2008). (3) The constitutive arm of the immune function has both cellular (i.e. leukocytes) and soluble components (e.g. acute phase proteins and antibodies). It is possible that the trade-off between strenuous exercise and immune function happens at the soluble but not at the cellular level of the constitutive arm. (4) The effect of migratory flight is masked by the effect of stress. Handling and blood sampling is thought to be an acute stressor, which triggers changes in leukocyte profiles (Davis, 2005; Davis et al., 2008; Dhabhar, 2002; Dhabhar et al., 1995; Gross and Siegel, 1983). However, because our handling times never exceeded $30 \mathrm{~min}$, this effect should be minimal (Buehler et al., 2008a). (5) Finally, the blood that was used to make the smears had come into contact with heparin. We chose heparin because other anticoagulants (such as EDTA) can cause haemolysis in bird species (Campbell and Ellis, 2007), which negatively affects haemolysishaemagglutination and haptoglobin assays. However, heparin may cause clumping of leukocytes and thrombocytes, which may have increased the variability in our counts.

We showed not only that the indicators of the soluble constitutive immune system are lower in the post-flight than in the untrained group but also that haptoglobin decreased with increasing flight duration. Haptoglobin binds iron (haeme), which prevents it from participating in free radical chain reactions (Dobryszychka, 1997; Gutteridge, 1987) and from serving as a nutrient for invading bacteria (Exton, 1997). Iron is also an important promoter of oxidative stress during exercise (Cooper et al., 2002). Haptoglobin appears to play an important physiological role as an antioxidant, particularly during haemolysis, i.e. the breakdown of red blood cells (Lim et al., 2000). Exercise-induced haemolysis is well documented in humans (Sentürk et al., 2005), and has been suggested to occur in birds (Landys-Ciannelli et al., 2002; Piersma et al., 1996). If haptoglobin levels are depleted by binding to oxidative iron during migration, this may explain the decrease in haptoglobin we found with increasing flight duration. One implication of this finding is that haptoglobin may not be available to offer protection against harmful end products of the immune response (Delers et al., 1988) during stopover immediately after a long flight.

Our results are in contrast to those of Hasselquist and colleagues, who found no effect of prolonged flight in a wind tunnel on immune function in red knots (Hasselquist et al., 2007). They measured cellmediated and humoral acquired induced immunity, while our study measured indicators of the innate constitutive response. The difference in results may reflect the different costs of the various aspects of the immune system during maintenance and use. Acquired, induced immunity is expensive to develop, but cheap to maintain and use, while innate constitutive immunity is cheap to develop and use and of medium cost to maintain (Klasing, 2004; Lee, 2006). It may thus be that a trade-off between exercise and immune function only becomes apparent at the level of maintaining (as opposed to developing or using) the different arms of the immunity. Another possible explanation is that, like in humans, acquired induced immunity in birds may not respond to exercise to the same degree as innate immunity (Nieman and Pedersen, 1999). Or there could be a trade-off between the different arms of the immune system itself (Buehler et al., 2009; Klasing, 2004; SchmidHempel and Ebert, 2003).

Our study has implications for the transmission of avian-borne diseases. Migrating birds can become long-range vectors for any bacterium, virus or parasite that they carry (Reed et al., 2003). Studies on avian malaria in migratory shorebirds have shown a low prevalence for the parasite (Earle and Underhill, 1993; Mendes et al., 2005; Peirce, 1981). Parasite infection could simply be a rare occurrence but it is also possible that infected individuals do not migrate. In this context it is interesting to note that migration distance was inversely related to parasite prevalence in monarch butterflies Danaus plexippus (Altizer et al., 2000), and to the intensity of infection with warble fly larvae, Hypoderma tarandi, in reindeer, 
Rangifer tarandus (Folstad et al., 1991). While migration may be a behavioural adaptation to reduce parasitic infection (Altizer et al., 2011; Folstad et al., 1991), it may also be possible that infected individuals are not capable of migrating as far as healthy ones, suggesting the same trade-off between immune function and migration in other taxa.

The next step will now be to test whether the reported trade-off between prolonged flight and constitutive immune function makes migrating birds more susceptible to infections and whether infections hamper their ability to perform long-distance migrations. Because of the recent emergence of avian-borne diseases such as West Nile virus (Marra et al., 2004), severe acute respiratory syndrome (SARS) and avian influenza (Liu et al., 2005), understanding the trade-offs and challenges faced by long-distance migrants has gained a new level of relevance and urgency.

\section{ACKNOWLEDGEMENTS}

We thank Alexander Macmillan for performing the differential leukocyte counts, W. Bezner-Kerr for assistance with wind tunnel operations and M. Rebuli for help with animal care. Liam McGuire provided statistical advice.

\section{FUNDING}

Funding was provided to S.R.M. by the US National Science Foundation [grant no. IOS-0748349], the United States Department of Agriculture [grant no. RIAES538748] and the University of Rhode Island, and to C.G.G. by the Natural Science and Engineering Council of Canada [NSERC Discovery Grant; 311901-2005 RGPIN], the Canada Foundation for Innovation [grant no. 11826], the Ontario Research Fund [grant no. 11743], and the University of Western Ontario Academic Development Fund [grant no. SG10-18]. D.M.B. was supported by the Natural Science and Engineering Council of Canada [NSERC grant no. PDF373488-2009] and the Netherlands Organisation for Scientific Research [NWO; Rubicon 825.09.0190].

\section{REFERENCES}

Alonso-Alvarez, C. and Tella, J. L. (2001). Effects of experimental food restriction and body mass changes on the avian T-cell-mediated immune response. Can. J. Zool. 79, 101-105.

Altizer, S., Bartel, R. and Han, B. A. (2011). Animal migration and infectious disease risk. Science 331, 296-302.

Altizer, S. M., Oberhauser, K. S. and Brower, L. P. (2000). Associations between host migration and the prevalence of a protozoan parasite in natural populations of adult monarch butterflies. Ecol. Entom. 25, 125-139.

Apanius, V. (1998). Stress and immune defense. In Stress and Behavior, Vol. 27 (ed. A. P. Møller M. Milinski and P. J. B. Slater), pp. 133-153. San Diego: Academic Press.

Ardia, D. R. (2005). Tree swallows trade off immune function and reproductive effort differently across their range. Ecology 86, 2040-2046.

Ardia, D. R. and Schat, K. A. (2008). Ecoimmunology. In Avian Immunology (ed. F. Davison, B. Kaspers and K. A. Schat), pp. 421-465. Amsterdam: Academic Press.

Baj, Z., Kantorski, J., Majewska, E., Zeman, K., Pokoca, L., Fornalczyke, E., Tchorzewski, H., Sulowska, Z. and Lewicki, R. (1994). Immunological status of competitive cyclists before and after the training season. Int. J. Sports Med. 15, 319324.

Buehler, D. M. and Piersma, T. (2008). Travelling on a budget: predictions and ecological evidence for bottlenecks in the annual cycle of long-distance migrants. Philos. Trans. R. Soc. Lond. B 363, 247-266.

Buehler, D. M., Bhola, N., Barjaktarov, D., Goymann, W., Schwabl, I., Tieleman, B. I. and Piersma, T. (2008a). Constitutive immune function responds more slowly to handling stress than corticosterone in a shorebird. Physiol. Biochem. Zool. 81, 673681 .

Buehler, D. M., Piersma, T., Matson, K. and Tieleman, B. I. (2008b). Seasonal redistribution of immune function in a migrant shorebird: annual-cycle effects override adjustments to thermal regime. Am. Nat. 172, 783-796.

Buehler, D. M., Encinas-Viso, F., Petit, M., Vézina, F., Tieleman, B. I. and Piersma T. (2009). Limited access to food and physiological trade-offs in a long-distance migrant shorebird. Part II: constitutive immune function and the acute phase response. Physiol. Biochem. Zool. 82, 561-571.

Buehler, D. M., Tieleman, B. I. and Piersma, T. (2010a). How do migratory species stay healthy over the annual cycle? A conceptual model for immune function and for resistance to disease. Integr. Comp. Biol. 50, 261-279.

Buehler, D. M., Tieleman, B. I. and Piersma, T. (2010b). Indices of immune function are lower in red knots (Calidris canutus) recovering protein than in those storing fat during stopover in Delaware Bay. Auk 127, 394-401.

Butler, P. J. and Woakes, A. J. (1990). The physiology of bird flight. In Bird Migration: Physiology and Ecophysiology (ed. E. Gwinner), pp. 300-318. Heidelberg, Berlin: Springer.

Campbell, T. W. (1995). Avian Hematology and Cytology. Ames, lowa: lowa State University Press.
Campbell, T. W. and Ellis, C. (2007). Avian and Exotic Animal Hematology and Cytology. Ames, lowa: Blackwell Publishing.

Cardinet, G. H., Littrell, J. F. and Schalm, O. W. (1964). Effects of sustained muscular activity upon blood morphology of the horse. Calif. Vet. 18, 31-35.

Cooper, C. E., Vollaard, N. B. J., Choueiri, T. and Wilson, M. T. (2002). Exercise, free radicals and oxidative stress. Biochem. Soc. Trans. 30, 280-285.

Davis, A. K. (2005). Effect of handling time and repeated sampling on avian white blood cell counts. J. Field Ornithol. 76, 334-338.

Davis, A. K., Maney, D. L. and Maerz, J. C. (2008). The use of leukocyte profiles to measure stress in vertebrates: a review for ecologists. Funct. Ecol. 22, 760-772.

Deerenberg, C., Arpanius, V., Daan, S. and Bos, N. (1997). Reproductive effort decreases antibody responsiveness. Proc. R. Soc. Lond. B 264, 1021-1029.

Delers, F., Strecker, G. and Engler, R. (1988). Glycosylation of chicken haptoglobin: isolation and characterization of three molecular variants and studies of their distribution in hen plasma before and after turpentine-induced inflammation. Biochem. Cell Biol. 66, 208-217.

Dhabhar, F. S. (2002). A hassle a day may keep the doctor away: stress and the augmentation of immune function. Integr. Comp. Biol. 42, 556-564.

Dhabhar, F. S., Miller, A. H., McEwen, B. S. and Spencer, R. L. (1995). Effects of stress on immune cell distribution. Dynamics and hormonal mechanisms. J. Immunol. 154, 5511-5527.

Dobryszychka, W. (1997). Biological functions of haptoglobin-new pieces to an old puzzle. Eur. J. Clin. Chem. Clin. Biochem. 35, 647-654.

Dolbeer, R. A. (1982). Migration patterns for age and sex classes of blackbirds and starlings. J. Field Ornithol. 53, 28-46.

Earle, R. A. and Underhill, L. G. (1993). Absence of haematozoa in some charadriiformes breeding in the Taimyr Peninsula, Russia. Ardea 81, 21-24.

Exton, M. S. (1997). Infection-induced anorexia: active host defence strategy. Appetite 29, 369-383.

Folstad, I., Nilssen, A. C. and Andersen, J. (1991). Parasite avoidance: the cause of post-calving migrations in Rangifer? Can. J. Zool. 69, 2423-2429.

Gerson, A. R. and Guglielmo, C. G. (2011). Flight at low ambient humidity increases protein catabolism in migratory birds. Science 333, 1434-1436.

Gleeson, M. (2007). Immune function in sport and exercise. J. Appl. Physiol. 103, 693699

Gleeson, M., Mcdonald, W. A., Cripps, A. W., Pyne, D. B., Clancy, R. L. and Fricker, P. A. (1995). The effect of immunity of long-term intensive training in elite swimmers. Clin. Exp. Immunol. 102, 210-216.

Graham, A. L., Hayward, A. D., Watt, K. A., Pilkington, J. G., Pemberton, J. M. and Nussey, D. H. (2010). Fitness correlates of heritable variation in antibody responsiveness in a wild mammal. Science 330, 662-665.

Gross, W. B. and Siegel, H. S. (1983). Evaluation of the heterophil/lymphocyte ratio as a measure of stress in chickens. Avian Dis. 27, 972-979.

Gutteridge, J. M. C. (1987). The antioxidant activity of haptoglobin towards haemoglobin-stimulated lipid peroxidation Biochim. Biophys. Acta 917, 219-223.

Hasselquist, D., Lindström, Å., Jenni-Eiermann, S., Koolhaas, A. and Piersma, T. (2007). Long flights do not influence immune responses of a long-distance migrant bird: a wind-tunnel experiment. J. Exp. Biol. 210, 1123-1131.

Hoffmann, D., Wolfarth, B., Hörterer, H. G., Halle, M., Reichhuber, C., Nadas, K., Tora, C., Erfle, V., Protzer, U. and Schätzl, H. M. (2010). Elevated epstein-barr virus loads and lower antibody titers in competetivie athletes. J. Med. Virol. 82, 446451.

Johnson, C. R. and Field, C. C. (1993). Using fixed-effects model multivariate analysis of variance in marine biology and ecology. Oceanogr. Mar. Biol. Annu. Rev. 31, 177-221.

Juul-Madsen, H. R., Viertlboeck, B., Smith, A. L. and Göbel, T. W. F. (2008). Avian innate immune resonses. In Avian Immunology (ed. F. Davison, B. Kaspers and K. A. Schat), pp. 129-158. Amsterdam: Academic Press.

King, J. R. (1974). Seasonal allocation of time and energy resources in birds. In Avian Energetics, Vol. 15 (ed. R. A. J. Paynter), pp. 4-85. Cambridge, MA: Nuttall Ornithological Club.

Klasing, K. C. (1998). Avian macrophages: regulators of local and systemic immune responses. Poultry Sci. 77, 983-989.

Klasing, K. C. (2004). The costs of immunity. Acta Zool. Sinica 50, 961-969.

Kraaijeveld, A. R., Limentani, E. C. and Godfray, H. C. J. (2001). Basis of the tradeoff between parasitoid resistance and larval competitive ability in Drosophila melanogaster. Proc. R. Soc. Lond. B 268, 259-261.

Landys-Ciannelli Jukema, J. and Piersma, T. (2002). Blood parameter changes during stopover in a long-distance migratory shorebird, the bar-tailed godwit Limosa lapponica taymyrensis. J. Avian Biol. 33, 451-455.

Lee, K. A. (2006). Linking immune defenses and life history at the levels of the individual and the species. Integr. Comp. Biol. 46, 1000-1015.

Lim, Y. K., Jenner, A., Ali, A. B., Wang, Y., Hsu, S. I.-H., Chong, S. M., Baumman H., Halliwell, B. and Lim, S.-K. (2000). Haptoglobin reduces renal oxidative DNA and tissue damage during phenylhydrazine-induced hemolysis. Kidney Int. 58, 10331044.

Liu, J., Xiao, H., Lei, F., Zhu, Q., Qin, K., Zhang, X.-w., Zhang, X.-I., Zhao, D., Wang, G., Feng, Y. et al. (2005). Highly pathogenic H5N1 influenza virus infection in migratory birds. Science 309, 1206.

Lochmiller, R. L. and Deerenberg, C. (2000). Trade-offs in evolutionary immunology: just what is the cost of immunity? Oikos $\mathbf{8 8}, 87-98$

López, P. and Martín, J. (2005). Female Iberian wall lizards prefer male scents that signal a better cell-mediated immune response. Biol. Lett. 1, 404-406.

Marra, P. P., Griffing, S., Caffrey, C., Kilpatrick, A. M., McLean, R., Brand, C., Saito, E., Dupuis, A. P., Kramer, L. and Novak, R. (2004). West Nile Virus and wildlife. Bioscience 54, 393-402.

Martin, L. B., Weil, Z. M. and Nelson, R. J. (2008). Seasonal changes in vertebrate immune activity: mediation by physiological trade-offs. Philos. Trans. R. Soc. Lond. B $363,321-339$. 
Martin, L. B. I. (2005). Trade-offs between molt and immune activity in two populations of house sparrows (Passer domesticus). Can. J. Zool. 83, 780-787.

Matson, K. D. (2006). Are there differences in immune function between continental and insular birds? Proc. R. Soc. Lond. B 273, 2267-2274.

Matson, K. D., Ricklefs, R. E. and Klasing, K. C. (2005). A hemolysishemagglutination assay for characterizing constitutive innate humoral immunity in wild and domestic birds. Dev. Comp. Immunol. 29, 275-286.

Mauck, R. A., Matson, K. D., Philipsborn, J. and Ricklefs, R. E. (2005). Increase in the constitutive innate humoral immune system in Leach's storm-petrel (Oceanodroma leucorhoa) chicks is negatively correlated with growth rate. Funct. Ecol. 19, 1001-1007.

Mendes, L., Piersma, T., Lecoq, M., Spaans, B. and Ricklefs, R. E. (2005) Disease-limited distributions? Contrasts in the prevalence of avian malaria in shorebird species using marine and freshwater habitats. Oikos 109, 396-404.

Moreno, J., Sanz, J. J. and Arriero, E. (1999). Reproductive effort and T-lymphocyte cell-mediated immunocompetence in female pied Flycatchers Ficedula hypoleuca. Proc. R. Soc. Lond. B 266, 1105-1109.

Nieman, D. C. (1997). Exercise immunology: practical applications. Int. J. Sports Med 18, S91-S100.

Nieman, D. C. and Pedersen, B. K. (1999). Exercise and immune function: recent developments. Sports Med. 27, 73-80.

Nieman, D. C., Buckley, K. S., Henson, D. A., Warren, B. J., Suttles, J., Ahle, J. C., Simandle, S., Fagoaga, O. R. and Nehlsen-Cannarella, S. L. (1995). Immune function in marathon runners versus sedentary controls. Med. Sci. Sports Exerc. 27 986-992.

Norris, K. and Evans, M. R. (2000). Ecological immunology: life history trade-offs and immune defense in birds. Behav. Ecol. 11, 19-26.

Ochsenbein, A. F. and Zinkernagel, R. M. (2000). Natural antibodies and complement link innate and acquired immunity. Immunol. Today 21, 624-630.

Olson, C. L. (1976). On choosing a test statistic in multivariate analysis of variance. Psychol. Bull. 83, 579-586.

Pedersen, B. K. and Hoffmann-Goetz, L. (2000). Exercise and the immune system: regulation, integration, and adaptation. Physiol. Rev. 80, 1055-1081.

Peirce, M. A. (1981). Distribution and host-parasite check-list of the haematozoa of birds in western Europe. J. Nat. Hist. 15, 419-458.

Piersma, T., Everaarts, J. M. and Jukema, J. (1996). Build-up of red blood cells in refuelling bar-tailed godwits in relation to individual migratory quality. Condor 98 363-370
Reed, K. D., Meece, J. K., Henkel, J. S. and Shukla, S. K. (2003). Birds, migration and emerging zoonoses: West Nile virus, Lyme disease, influenza $A$ and enteropathogens. Clin. Med. Res. 1, 5-12.

Rolff, J. and Siva-Jothy, M. T. (2003). Invertebrate ecological immunology. Science 301, 472-475.

Sanz, J. J., Moreno, J., Merino, S. and Tomás, G. (2004). A trade-off between two resource-demanding functions: post-nuptial moult and immunity during reproduction in male pied flycatchers. J. Anim. Ecol. 73, 441-447.

Schmid-Hempel, P. and Ebert, D. (2003). On the evolutionary ecology of specific immune defence. Trends Ecol. Evol. 18, 27-32.

Sentürk, U. K., Gündüz, F., Kuru, O., Koçer, G., Ozkaya, Y. G., Yesilkaya, A., BorKüçükatay, M., Uyüklü, M., Yalçin, O. and Baskurt, O. K. (2005). Exerciseinduced oxidative stress leads hemolysis in sedentary but not trained humans. J. Appl. Physiol. 99, 1434-1441.

Sheldon, B. C. and Verhulst, S. (1996). Ecological immunology: costly parasite defences and trade-offs in evolutionary ecology. Trends Ecol. Evol. 11, 317-321.

Sokal, R. R. and Rohlf, F. J. (1995). Biometry. New York: W. H. Freeman and Company

Tella, J. L., Scheuerlein, A. and Ricklefs, R. E. (2002). Is cell-mediated immunity related to the evolution of life-history strategies in birds? Proc. R. Soc. Lond. B 269 1059-1066.

Tvede, N., Steensberg, J., Baslund, B., Halkjaer Kristensen, J. and Pedersen, B. K. (1991). Cellular immunity in highly trained elite racing cyclists during periods of training with high and low intensity. Scand. J. Med. Sci. Sports 1, 163-166.

van Gils, J. A., Munster, V. J., Radersma, R., Liefhebber, D., Fouchier, R. A. M. and Klaassen, M. (2007). Hampered foraging and migratory performance in swans infected with low-pathogenic avian influenza A virus. PLOS ONE 2, e184.

Willmer, P., Stone, G. and Johnston, I. (2000). Environmental Physiology of Animals. Oxford: Blackwell Science.

Wolach, B., Eliakim, A., Gavrieli, R., Kodesh, E., Yarom, Y., Schlesinger, M. and Falk, B. (1998). Aspects of leukocyte function and the complement system following aerobic exercise in young female gymnasts. Scand. J. Med. Sci. Sports 8 91-97.

Zar, J. H. (1999). Biostatistical Analysis. New Jersey: Prentice Hall.

Zuur, A. F., leno, E. N., Walker, N. J., Saveliev, A. A. and Smith, G. M. (2009) Mixed Effects Models and Extensions in Ecology with R. New York: Springer. 